\section{Novel use of rituximab in hypersensitivity pneumonitis refractory to conventional treatment}

Hypersensitivity pneumonitis (HP) is treated by removal of the inciting antigen, if identified, and with corticosteroids and immunosuppressive agents in extensive or progressive disease. A minority of patients continue to decline and suffer outcomes comparable to idiopathic pulmonary fibrosis. Rituximab, a B cell depleting anti-CD20 antibody, has shown benefit in interstitial lung diseases (ILDs) associated with connective tissue diseases (CTDs). ${ }^{1-3}$ We report a novel use of rituximab in a case of HP refractory to conventional treatment.

A 57-year-old female never-smoker, with no previous medical history, presented with a 6-month history of progressive breathlessness and dry cough. Pulmonary function tests (PFTs) were impaired, with $26 \%$ of diffusing capacity for carbon monoxide (DLco) and 44\% of forced vital capacity (FVC). A high-resolution CT (HRCT) showed changes suggestive of HP (figure 1A). A surgical lung biopsy disclosed chronic bronchocentric inflammation, poorly formed non-necrotising granulomas and mild fibrosis (figure 1B). Immunohistochemistry showed scattered CD20 follicular aggregates on a background of CD3 T cells. A causative exposure was not identified on clinical history, precipitin screening tests were negative and features of a CTD were absent. HP was diagnosed with high confidence by multidisciplinary consensus. Oral prednisolone was commenced, tapering from $40 \mathrm{mg}$ daily to maintenance $20 \mathrm{mg}$ daily over 2 weeks. Following continued deterioration over the next 4 months, three $500 \mathrm{mg}$ doses of intravenous methylprednisolone were administered weekly, followed by six 3-weekly doses of intravenous cyclophosphamide $\left(600 \mathrm{mg} / \mathrm{m}^{2}\right.$ of body surface area).

Twelve months after presentation, and despite vigorous immunosuppressant treatment, PFTs had further worsened DLco and FVC, reaching a nadir of $17 \%$ and $37 \%$, respectively. Exercise tolerance was only $15 \mathrm{~m}$ despite ambulatory oxygen. Repeat HRCT demonstrated progression of
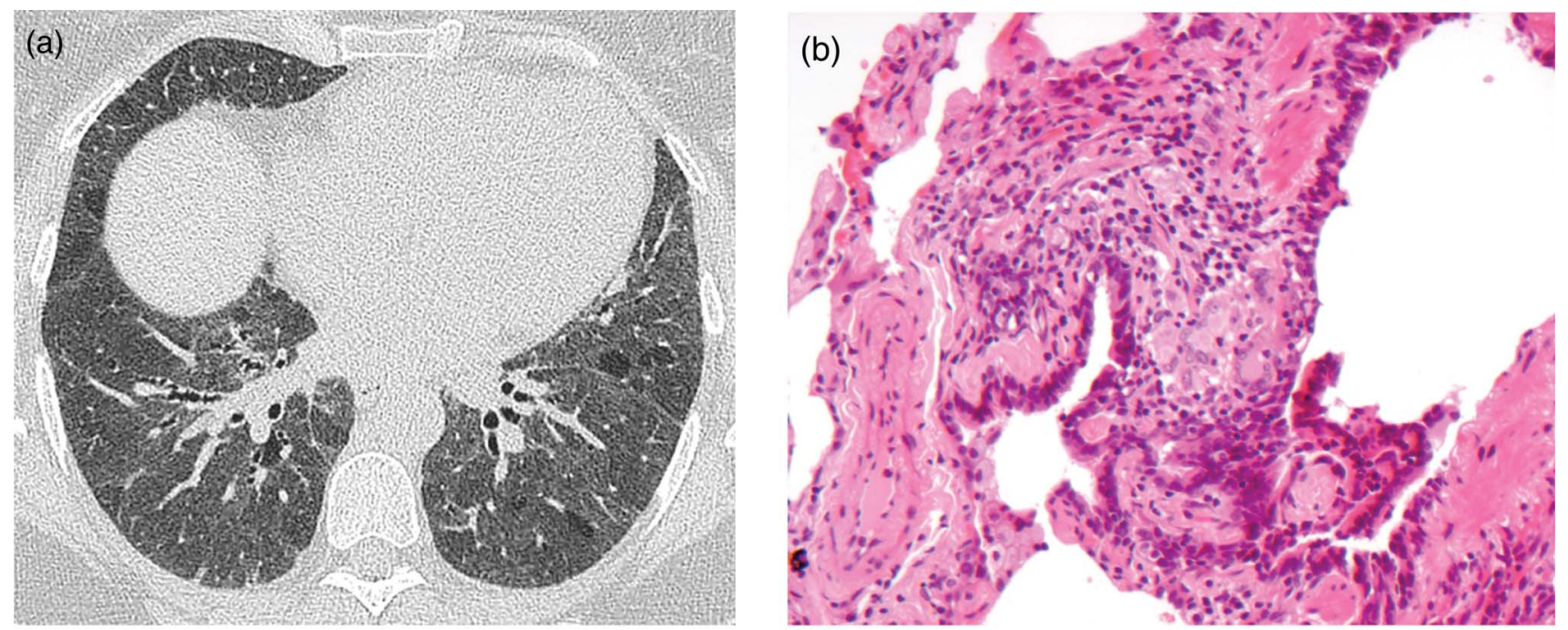

(c)

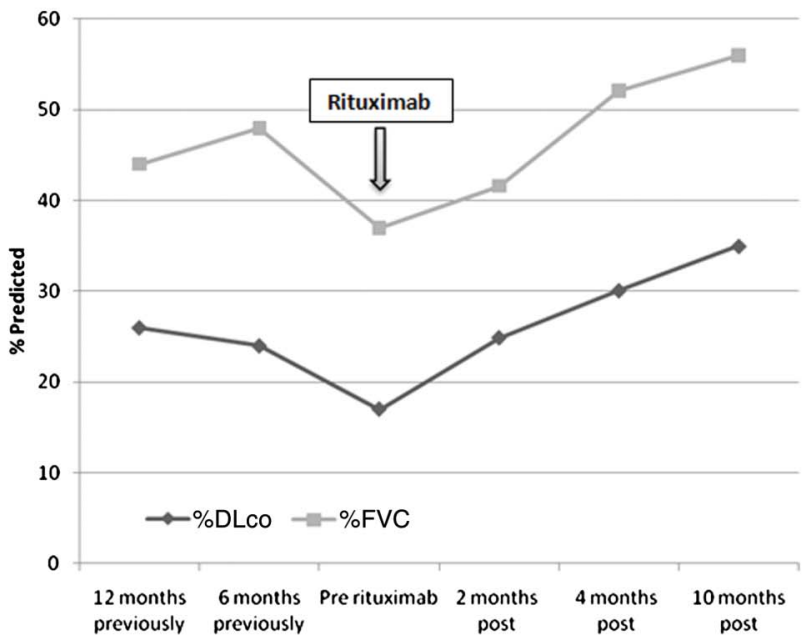

Figure 1 (A) Section through lower lobes showing generally increased attenuation of lung parenchyma with a few pulmonary lobules of decreased attenuation (reflecting small airway component). Appearances typical of hypersensitivity pneumonitis (HP). Both lower lobes are of reduced volume; in the right lower lobe, there is subtle traction bronchiectasis reflecting fine interstitial fibrosis. (B) A bronchiole shows moderate chronic inflammation and a small poorly formed non-necrotising granuloma in its wall, typical of HP $\left(H \& E_{1} \times 200\right)$. (C) Improvement in lung function following rituximab. FVC, forced vital capacity; DLco, diffusing capacity for carbon monoxide 
fibrosis. Further intravenous methylprednisolone $(500,750,750 \mathrm{mg}$ on consecutive days) was administered together with rituximab (1000 mg repeated after 2 weeks). Oral prednisolone followed, tapering from $30 \mathrm{mg}$ daily to a $10 \mathrm{mg}$ daily maintenance. Two months post rituximab, symptomatic improvement was reported with a corresponding improvement in PFTs (figure 1C). At 4 months, ambulatory oxygen was no longer required. Compared with the pre-rituximab results, DLco had risen by $76.5 \%$ to $30 \%$ and FVC by $40.5 \%$ to $52 \%$. At 8 months, azathioprine $50 \mathrm{mg}$ daily was added as maintenance therapy. PFT improvement was sustained at 10 months. Our patient's striking improvement was temporally related to rituximab. Although administered concurrently, earlier treatment with methylprednisolone had been ineffective.

The unequivocal response to B cell depletion therapy suggests an immunopathogenetic role for B cells in HP. Although the inflammatory infiltrate in $\mathrm{HP}$ is traditionally considered to be $\mathrm{T}$ cell predominant, autoreactive $\mathrm{B}$ cells may originate from the $\mathrm{T}$ cell zone, accounting for the poorly organised lymphoid struc- ture in HP lungs. Furthermore, marked expansion of plasma cells has been observed in bronchoalveolar lavage, bronchus-associated lymphoid tissue and $\mathrm{B}$ cells ${ }^{4}$ and high titres of rheumatoid factor have been associated with pigeon fancier's lung suggesting B cell activation. ${ }^{5}$

This first report of the success of B cell depletion therapy in HP, if confirmed by future studies, widens the range of ILDs that might benefit from rituximab and suggests that immunological overactivity may drive ILD progression outside the context of autoimmune disease.

Harpreet K Lota, ${ }^{1}$ Gregory J Keir, ${ }^{1}$

David M Hansell, ${ }^{2}$ Andrew G Nicholson, ${ }^{3}$

Toby M Maher, ${ }^{1}$ Athol U Wells,

Elisabetta A Renzoni

${ }^{1}$ Interstitial Lung Disease Unit, Royal Brompton Hospital, London, UK

${ }^{2}$ Department of Radiology, Royal Brompton Hospital, London, UK

${ }^{3}$ Department of Histopathology, Royal Brompton Hospital, London, UK

Correspondence to Dr Harpreet K Lota, Interstitial Lung Disease Unit, Royal Brompton Hospital, Sydney Street, London SW3 6NP, UK; h.lota@rbht.nhs.uk

Contributors All authors contributed to this case report.
Competing interests None.

Patient consent Obtained.

Provenance and peer review Not commissioned; internally peer reviewed.

To cite Lota HK, Keir GJ, Hansell DM, et al. Thorax 2013;68:780-781.

Received 15 January 2013

Revised 19 February 2013

Accepted 21 February 2013

Published Online First 20 March 2013

Thorax 2013;68:780-781.

doi:10.1136/thoraxjn-2013-203265

\section{REFERENCES}

1 Sem M, Molberg O, Lund MB, et al. Rituximab treatment of the anti-synthetase syndrome: a retrospective case series. Rheumatology (Oxford) 2009;48:968-71.

2 Daoussis D, Liossis SN, Tsamandas AC, et al. Experience with rituximab in scleroderma: results from a 1-year, proof-of-principle study. Rheumatology (Oxford) 2010;49:271-80.

3 Keir GJ, Maher TM, Hansell DM, et al. Severe interstitia lung disease in connective tissue disease: rituximab as rescue therapy. Eur Respir J 2012;40:641-8.

4 Suda T, Chida K, Hayakawa H, et al. Development of bronchus-associated lymphoid tissue in chronic hypersensitivity pneumonitis. Chest 1999;115:357-63.

5 Aguilar León DE, Novelo Retana V, MartínezCordero E. Anti-avian antibodies and rheumatoid factor in pigeon hypersensitivity pneumonitis. Clin Exp Allergy 2003;33:226-32. 